\title{
Characterization of membrane-bound fatty acid desaturases
}

\author{
Tatiana Klempova ${ }^{1}$, Daniel Mihalik ${ }^{2}$ and Milan Certik ${ }^{1}$ \\ ${ }^{1}$ Department of Biochemical Technology, Faculty of Chemical and Food Technology, Slovak University of Technology, \\ Radlinskeho 9, 81237 Bratislava, Slovak Republic \\ ${ }^{2}$ Plant Production Research Centre, Bratislavska 122, 92168 Piestany, Slovak Republic
}

\begin{abstract}
Membrane-bound desaturases play key role in metabolism of polyunsaturated fatty acids. Characterization of these enzymes and their genes is the first step in basic understanding of their proper functioning in living cells as well as in tailor-made preparation of highly-specific and highlyproductive strains of microorganisms interesting for applied biotechnology. It is also the crucial step in creation of transgenic agricultural crops with enhanced content of individual polyunsaturated fatty acids. Properties and applications of identified membrane-bound desaturases genes and enzymes are discussed in this review.
\end{abstract}

Key words: Desaturase — Polyunsaturated fatty acid

\begin{abstract}
Abreviations: ALA, $\boldsymbol{\alpha}$-linolenic acid; ARA, arachidonic acid; DGLA, dihommo- $\gamma$-linolenic acid; DHA, docosahexaenoic acid; DPA, docosapentaenoic acid; EPA, eicosapentaenoic acid; ETA, eicosatetraenoic acid; FAS, fatty acids synthase; GLA, $\gamma$-linolenic acid; His, histidine; LA, linoleic acid; PKS, polyketide synthase system; PUFAs, polyunsaturated fatty acids; SDA, stearidonic acid.
\end{abstract}

\section{Introduction}

Polyunsaturated fatty acids (PUFAs) play important roles as structural components of membrane phospholipids and precursors of eicosanoids of signalling molecules, including prostaglandins, thromboxanes and leukotriens (Spector 1999; Jump 2002). They are important in both medical and pharmaceutical fields, being involved in the human inflammatory response, reproductive functions, immune response, blood pressure regulation, cholesterol metabolism, and infant retinal and brain development (Horrobin 1992; Benatti et al. 2004).

Edible oils for human consumption are predominantly comprised of six common fatty acids: palmitic, palmitoleic, stearic, oleic, linoleic (LA) and $a$-linolenic acid (ALA) (Qiu and Meesapyodsuk 2009). Human body is able to convert fatty

Correspondence to: Tatiana Klempova, Department of Biochemical Technology, Faculty of Chemical and Food Technology, Slovak University of Technology, Radlinskeho 9, 81237 Bratislava, Slovak Republic

E-mail: tatiana.klempova@stuba.sk acid precursors from these substrates to both PUFA $\omega-6$ and $\omega$-3 classes such as $\gamma$-linolenic acid (GLA), dihommo- $\gamma$-linolenic acid (DGLA), arachidonic acid (ARA), eicosapentaenoic acid (EPA) and docosahexaenoic acid (DHA). However, the affectivities of these conversions are very poor especially for $\omega-3$ PUFAs. Certain fish oils can be rich source of PUFAs although processed marine oils are generally undesirable as food ingredients because of the associated objectionable flavours and contaminants that are difficult and cost- prohibitive to remove (Damude and Kinney 2007). PUFAs are currently produced from fish or cultivated microorganisms, but their high production cost and diminishing feedstock limit their supply and usage (Chen et al. 2006). To obtain a more suitable source of large-scale production of PUFAs, the study of PUFA's biosynthetic pathway and its subsequent genetic manipulation is challenging alternative.

Therefore, the main purposes of desaturases studies can be summarized as follows:

- preparation of highly specific oleaginous microorganisms that are suitable for fermentation production

- obtaining special plants with desired composition of PUFA. 


\section{Biosynthesis of PUFA}

Biosynthesis of PUFA is associated with both membranebound desaturase and elongation enzymes. Figure 1 represents the aerobic biosynthetic pathway of PUFAs. The first double bond is introduced into $\Delta 9$-position of saturated fatty acid, thus palmitoleic (C 16:1, n-7) and oleic (C 18:1, n-9) are the most common monoens in organisms. Oleic acid is then, in general, transformed by $\Delta 12$-desaturase to yield linoleic acid (LA; C 18:2, n-6), which may be further converted by $\Delta 15$ ( $\omega-3)$-desaturase to $\alpha$-linolenic acid (ALA; C 18:3, n-3). Thus, these fatty acids are the basic precursors of $n-6$ and $n-3$ fatty acid cascades. Next step is desaturation of these fatty acids by $\Delta 6$-desaturase. LA in n-6 pathway is converted to $\gamma$-linolenic acid (GLA, C 18:3, n-6) and ALA in n-3 pathway is converted into stearidonic acid (SDA; C 18:4, n-3). GLA and SDA are subsequently elongated in C20 fatty acid. GLA is elongated into dihommo- $\gamma$-linolenic acid (DGLA, C 20:3, $\mathrm{n}-6)$ and SDA into eicosatetraenoic acid (ETA, C 20:4, n-3). There occurs another desaturation step using $\Delta 5$-desaturase.
In $\mathrm{n}-6$ arachidonic acid (ARA, C 20:4, n-6) is synthesized and in n-3 pathway EPA (C 20:5, n-3) is synthesized. These two fatty acids go under elongation step to create C22 fatty acids with corresponding number of double bonds. Last step is catalyzed by $\Delta 4$-desaturase and docosapentaenoic acid (DPA; C 22:5, n-6) and docosahexaenoic acid (DHA, C 22:6, n-3) are produced. Each fatty acid desaturase introduces a double bond at the specific position of acyl chain (Los and Murata 1998). The $\Delta 9$-desaturase is the only universally spread desaturase being present in all living beings groups. The remaining desaturases are missing in some of the evolutionary lineages (Alonso 2003). These enzymes are spread into various types of organisms and only the certain groups of them contain each of them. The $\Delta 12$ - and $\Delta 15$-desaturase occurs only in marine bacteria and algae, cyanobacteria, zygomycetes fungi and higher plants. This distribution made LA and ALA 'essential fatty acids' for animal and $\Delta 9$-desaturase essential for life (Alonso et al. 2003). The $\Delta 6$ - and $\Delta 5$-desaturases are present only in marine bacteria and algae, zygomycetes fungi and animals. The $\Delta 4$-desaturase was identified only in marine

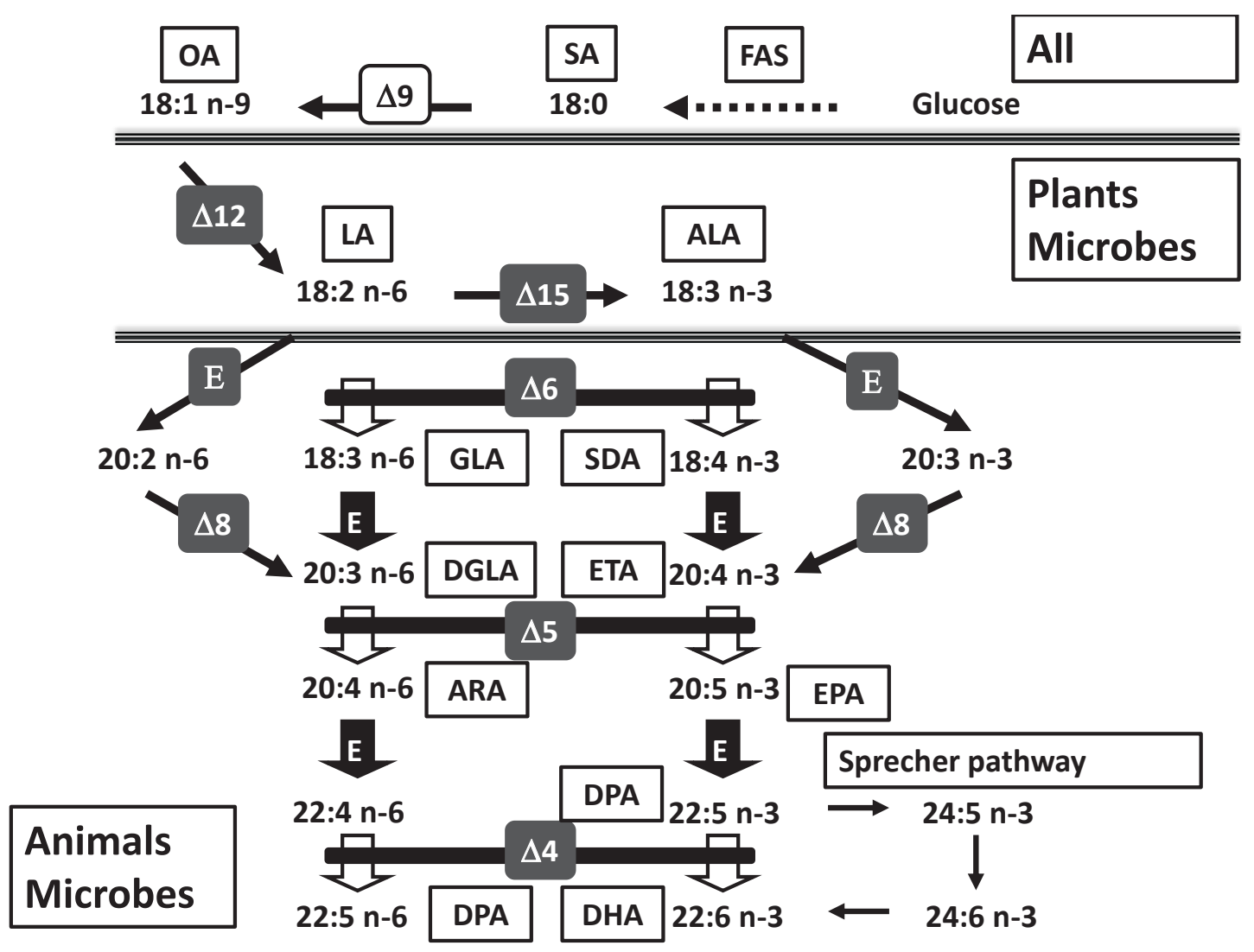

Figure 1. Aerobic biosynthetic pathway of PUFAs. FAS, fatty acid synthase system; SA, stearic acid; OA, oleic acid; LA, linoleic acid; ALA, alpha linolenic acid; GLA, gamma linolenic acid; SDA, stearidonic acid; DGLA, dihommo-gamma linolenic acid; ETA, eicosatetraenoic acid; ARA, arachidonic acid; EPA, eicosapentaenoic acid; DPA, docosapentaenoic acid (n-6 \& n-3); DHA, docosahexaenoic acid; E, elongase; $\Delta \mathrm{X}$, desaturation enzyme (the number express the carbon position in acyl chain where desaturation occurs). For more detailed description of pathway, see the text. 
Table 1. Comparison of certain type of fatty acid desaturases

\begin{tabular}{lcccc}
\hline Desaturase & Cytochrome b $_{5}$ domain & $1^{\text {st }}$ His-box & $2^{\text {nd }}$ His-box & $3^{\text {rd }}$ His-box \\
\hline$\Delta 4$ & N-terminal & HXXXH & HXXXHH & QXXHH \\
$\Delta 5$ & N-terminal & HXXXH & HXX $(X) H H$ & QXXHH \\
$\Delta 6$ & N-terminal & HXXXH & HXXHH & QXXHH \\
$\Delta 9$ & C-terminal & HXXXXH & HXXHH & HXXHH \\
$\Delta 12$ & does not contains & HXXXH & HXXHH & HXXHH \\
\hline
\end{tabular}

protists, algae and thraustochytrids such as Thraustochytrium sp. (Qiu et al. 2001), Thalassiosira (Tonon et al. 2005). Mammals use for last step "Sprecher pathway" instead of direct desaturation of C 22:5, n-3 to DHA. Sprecher pathway has three distinct step - first is elongation to $24: 5, \mathrm{n}-3$ followed by desaturation with $\Delta 6$-desaturase and then one $\beta$-oxidation step to DHA. In the late 90 's the alternative $\Delta 8$-pathway has been discover in some protists and algae species e.g. Euglena (Wallis and Browse 1999) or Isochrysis (Qi et al. 2002). This pathway involved the $\Delta 9$-elongation step of LA or ALA as first one followed by $\Delta 8$-desaturation to yield DGLA (in n-6 cascade) or ETA (in n-3 cascade).

PUFA are synthesised through both anaerobic and aerobic pathway. The desaturation system of the aerobic pathway is composed of three proteins: $\mathrm{NAD}(\mathrm{P}) \mathrm{H}$-cytochrome $\mathrm{b}_{5}$ reductase, cytochrome $b_{5}$ and the terminal cyanide-sensitive desaturase (Figure 2) (Certik and Shimizu 1999). The exception could be found in organisms from prokaryota group since they contain ferredoxin instead of cytochrome $\mathrm{b}_{5}$. The desaturation takes place in the endoplasmatic reticulum where fatty acid bound to phospholipids (especially phosphatidylcholine) are desaturated rather than thiol CoA ester (Pereira et al. 2003). Membrane-bound desaturases introduce double bond into fatty acids that are either esterified as acyl CoA or bound to the glycerol moiety of glycerolipids (Los and Murata 1998).

Anaerobic biosynthetic pathway of PUFA is carried out by specialized polyketide synthase (PKS) sometimes called FAS II system (fatty acid synthase II). FAS II is a complex of four discrete enzymes each with activities equivalent to FAS I system that is common in every cell. FAS I start with condensation of acetyl-CoA with malonyl-ACP by the beta-ketoacyl-ACP synthase (KS). This is followed by the reduction of the beta-ketoester by a NADPH-dependent beta-ketoacyl-ACP reductase, the removal of water by the beta-hydroxyacyl-ACP dehydrase to produce trans-2 enoyl$\mathrm{ACP}$ and another reduction by the enoyl-ACP reductase to form a saturated acyl-ACP that in turn can initiate another cycle of condensation with malonyl-ACP, reductions and dehydration. The process continues up to the synthesis of C 16-18 saturated acyl-ACPs. The shunt is produced by the action of a specific b-hydroxyacyl-ACP dehydrase that, in addition, has a trans-2-cis-3 isomerase activity on trans-2decenoyl-ACP that results in formation of cis-3-decenoylACP. Repetion of these steps results in synthesis of PUFA such as DHA. This pathway can be found in marine bacteria such as Shewanella or Photobacterium, and thraustochytrids such as Szichochytrium (Uttaro 2006). This strain is also an example of organisms that has possibility to synthesise PUFAs by anaerobic together with aerobic pathways.

\section{Fatty acid desaturases}

Membrane-bound desaturase have three conserved separated histidine (His) boxes and four transmembrane domains. His residues are assumed to be ligands for iron ions that are essential for catalytic place of desaturase. From topological point of view, each desaturase crosses the membrane four times in two hydrophobic domains and all three His boxes are on membrane of endoplasmatic reticulum towards cytosol (Stuckey et al. 1990; Shanklin and Cahoon 1998). This corresponds to suppose that His

\section{Endoplasmic reticulum (ER)}

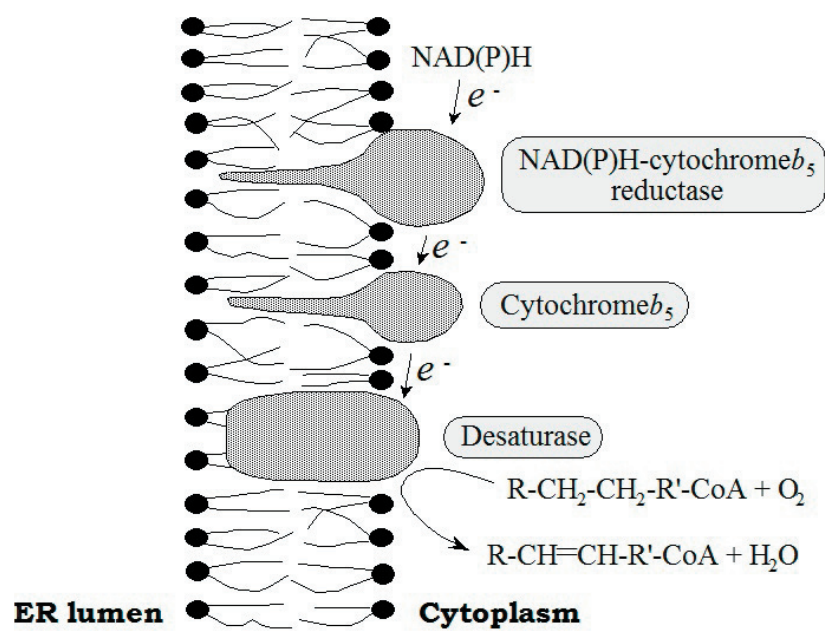

Figure 2. Desaturation system of aerobic biosynthesis of PUFAs (according to Certik and Shimizu 1999). 
boxes are the catalytic places for desaturation. Sperling et al. (2003) published review that identifies two groups of desaturases that differ in number of amino acids between $1^{\text {st }}$ and $3^{\text {rd }}$ His box. Experimental data obtain for acyl-lipid desaturase from Bacillus subtilis shown that this desaturase contains another hydrophobic domain (Diaz et al. 2002). On the other hand, data concerning topology of mouse stearoyl-coA desaturase shows that this enzyme contains only two hydrophobic regions (Man et al. 2006). Author suggested that the topology of each desaturase is dependent on form of the substrate - if the fatty acid is bound in phospholipids or if it is soluble as fatty acyl-CoA.

The cytochrome $b_{5}$ domain is an essential part of functional desaturase protein. The sequence that represents this domain is HPGG. It serves as a donor of electrons for introduction the double bond in to the fatty acid chain.
Any disruption of this domain results in inactivation of desaturase (Sayanova et al. 1997). Depends on certain type of desaturase, it appears on either $\mathrm{N}$-terminal or C-terminal end of desaturase. The reason of deletion of this domain in $\Delta 12$-desaturase is still unknown.

The His boxes are specific for each type of desaturase and their usual motifs are: $\mathrm{H}(\mathrm{X})_{3-4} \mathrm{H}, \mathrm{H}(\mathrm{X})_{2-3} \mathrm{HH}$ and $\mathrm{H} /$ $\mathrm{Q}(\mathrm{X})_{2} \mathrm{HH}$ (Table 1 ). The $3^{\text {rd }}$ His box of $\Delta 4-, \Delta 5$ - and $\Delta 6$-desaturase rather contains glutamine then His. The $1^{\text {st }}$ His box of $\Delta 9$-desaturase contains four amino acid residues between histidines rather than two. The $2^{\text {nd }}$ His box of $\Delta 4$-desaturase contains three amino acids residues between histidines even the other proteins contains two amino acids. The $2^{\text {nd }}$ His box of $\Delta 5$-desaturase contains typically two amino acid residues between His residues, but in some organisms is possible to found three amino acids residues between His residues.

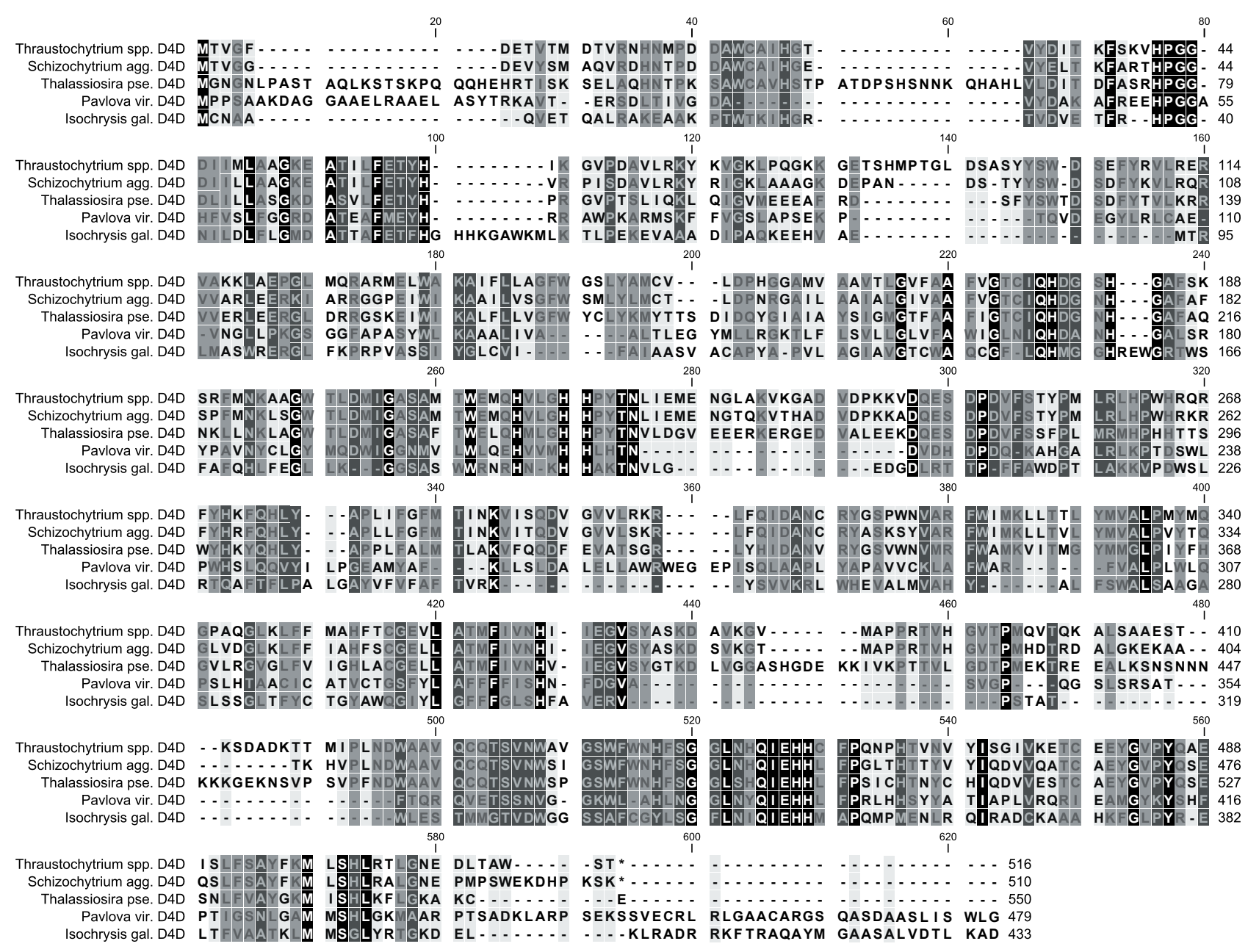

Figure 3. Alignment of amino acid sequences of $\Delta 4$-desaturase proteins (D4D) from following sources: Thraustochytrium spp., Schizochytrium aggregatum, Thalassiosira pseudonana, Pavlova viridis and Isochrysis galbana. Cytochrome $\mathrm{b}_{5}$ domain and His box are framed, degree of sequences conservation rises from light grey up to black (black, total conservation; dark grey, high conservation; middle grey, partial conservation; light grey, low conservation). For more details see Table 1. 
These changes suggest that 'front-end' desaturases has one common ancestor and through the evolution divide to three independent enzymes.

\section{4-desaturase}

$\Delta 4$-desaturase is enzyme that is responsible for biosynthesis of docosapentaenoic acid (DPA C 22:5, $\omega-6$ ) and DHA
(C 22:6, w-3). It was isolated from Thraustochytrium sp. (Qui et al. 2001; Zank et al. 2005), Schizochytrium aggregatum (Kinney et al. 2004), Isochrysis galbana (Pereira et al. 2004), Thalassiosira pseudonana (Tonon et al. 2005), Pavlova viridis (Xu et al. 2011). It has typical sign for 'front-end' desaturase $-\mathrm{Q}$ in $3^{\text {rd }}$ His box instead of $\mathrm{H}$, cytochrome $\mathrm{b}_{5}$ domain on $\mathrm{N}$-terminal, but in $2^{\text {nd }}$ His box contains one more amino acid residue (Fig. 3).

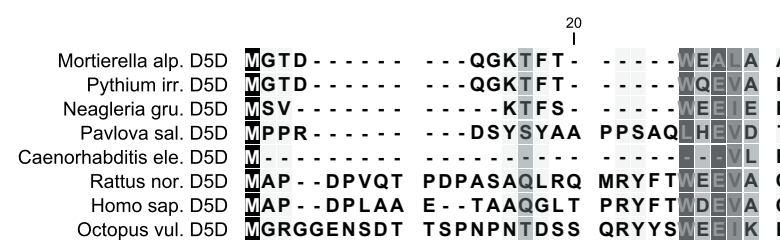

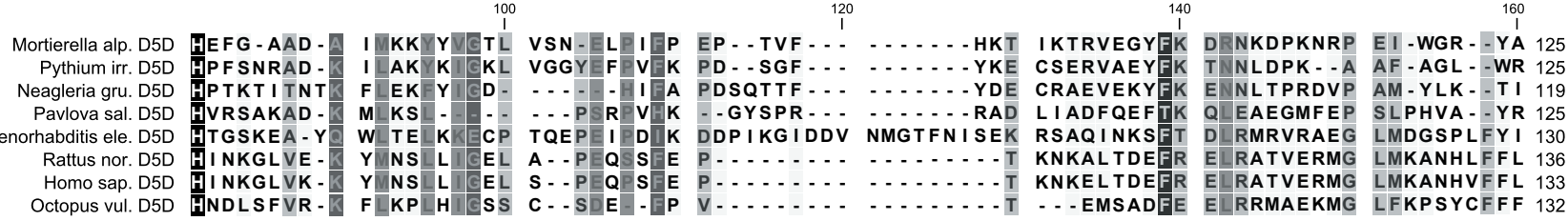

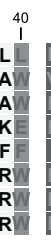

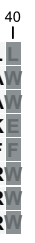

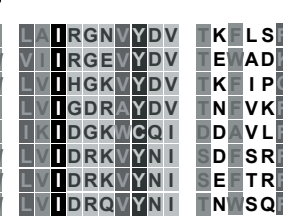

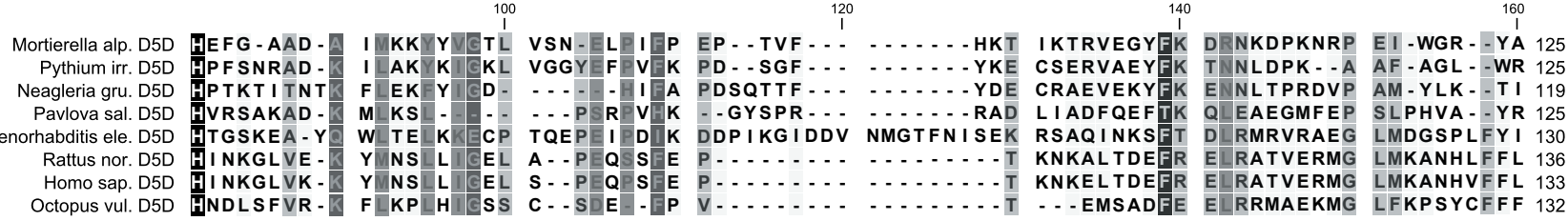

60

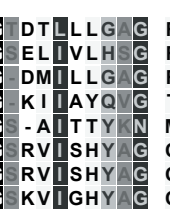

80 Octopus vul. D5D

180

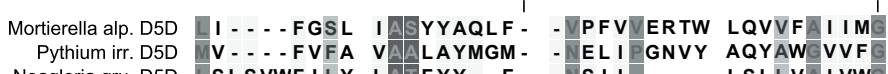

Neagleria gru. D5D LLSVWF ILY LATFYY - F - - NSII - . - LSLLVAIVWG

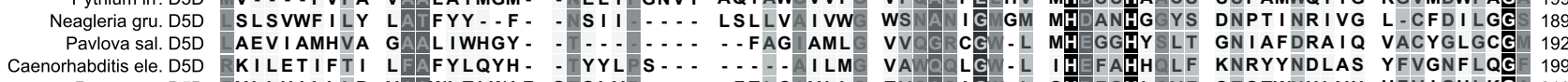

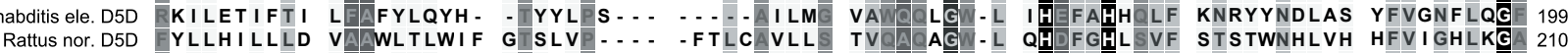

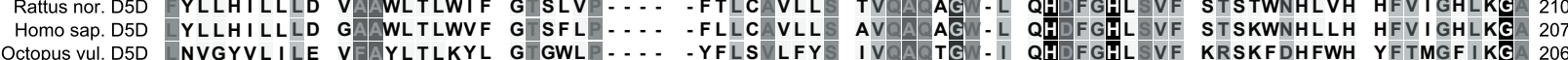

260 300 320

Mortierella alp. D5D SYLVWMYQHM LGHHPYTNIA GADPDVST - - - - S - EPDVR - R IKPNQ WF VNHINQHMFV PF- - LYGLLA FKVRIQDIN I 269 Pythium irr. D5D SMVSWLNQHV VGHH YTNVA GADPDLPV - - - - DFESDVR - R IVHRQVLL PIYKFQH I LL PP.- LYGVLG LKFRIQDVFE 271 Neagleria gru. D5D S - TMKMI HS VGHH NTNVE ERDPDIHT-- - - N - EPHFR -KIKEGQ QH WW SYQHIYL PF-. LYCTLL FELAFRDFAA 259

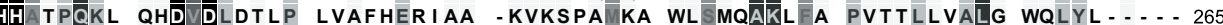
Caenorhabditis ele. D5D SSGGWKKEQHN V - HH ATNVV GRDGDLDLVP FYATVAEHLN - NYSQDS VMM TLFRQHVHW TFMLPFLRLS WLLQ- - - - - 271 Rattus nor. D5D ASWŪNHMHF Q-HH KPNCF RKDPINMHP LFFALGKVLS VELGKEK KH MP NHQHKYF FLIGPPALLP LYFQW-...-284 Homo sap. D5D ASWÑNHMHF Q-HH KPNCF RKDPDINMHP FFFALGKILS VELGKQK NY MP NHQHK F FLIGPPALLP LYFQW-.... 281

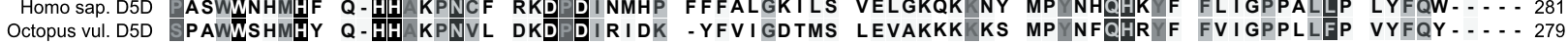
340 360
1 380 400

Mortierella alp. D5D LYFVKTNDAI RVN--PISTW - - - HTVMFW GGKAFFVWYR LIVPLQYLPL GKVLL- - LFT IADMVSSYWL ALTFGANHVV 341 Pythium irr. D5D TFVSLTNGPV RVNPH VSDW -... VQMIF - - AKAFWTFYR IYIPLVWLKI TPSTFWGVFF LAEFTT EWYL AFNFG SHVS 345

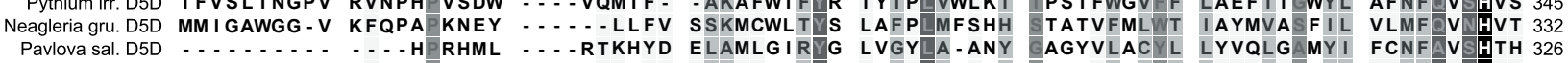
Caenorhabditis ele. D5D ........ II FVSQM THYY DYYRNTAIYE QVGLSLHWAW SLGQLYFLPD WSTRIM-FFL VSHLVG FLL SHVVTFNHYS 343 Rattus nor. D5D ................. I IF YFVVQRKKWV DLAWMLSFYV RVFFTYMPLL GLGLLCLFF IVRFLESNWF VWVT GMHIP 347 Rattus nor. D5D
Homo sap. D5D

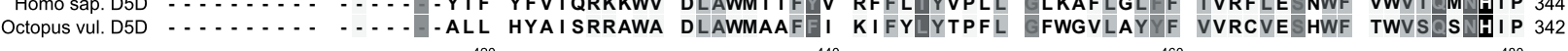
420 440

Mortierella alp. D5D EEVQWPLPD - - - - E - NG I I Q KDNAAMQVET TQ TYAHDSHL WTSITGSLNY Q AVHHLFP IV SQHHYPDILA IDKDTCSEYK 416 Pythium irr. D5D TECEYPCGD - - - APSAEVG DENAISQVKS SVDYAHGSPL AAFLCALNY Q THHLYPGI SQ H PAIAP IDIDV KKYN 421

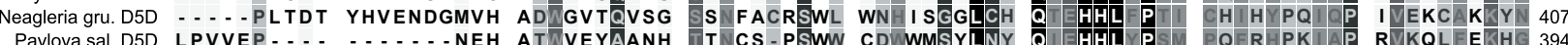

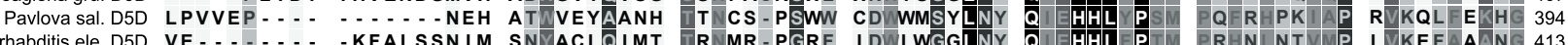

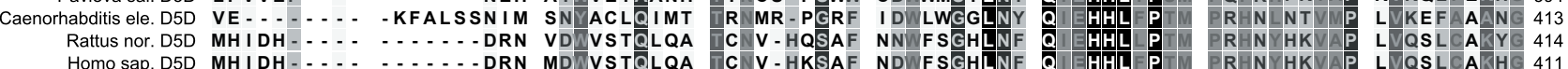

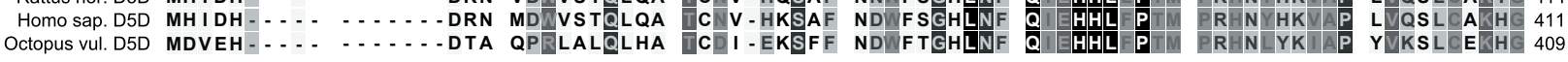
500

Mortierella alp. D5D VPYLVKDTFW QAFAS - - HLE HLEVLGL - - R R RE - - - E - 446 Pythium irr. D5D KYYT LPT T EALLA - - HFK HLKNME EL - G KPVE I HMG - 456 Neagleria gru. D5D RYNAY S W DAVVG--HFT LLKEMAAQ-G KKVTGWKDL 443 Pavlova sal. D5D HYDVR Y - EAMAD - - TFA NLDNAHA - P EKKM - - - Q Q 425 Caenorhabditis ele. D5D PYM D Y T GFWLEIEQFR NIANVAAK - L TKK IA - - - 447 Rattus nor. D5D KYESK L - TAFADIVY - - SLKES GLWL DAY - LHQ - 447 Homo sap. D5D IEYQSK LE- SAFADI IH-- SLESCQLWL DAY - LHQ - - 444

Figure 4. Alignment of amino acid sequences of $\Delta 5$-desaturase proteins (D5D) from Mortierella alpina, Pythium irregulare, Naegleria gruberi, Pavlova salina, Caenorhabditis elegans, Rattus norvegicus, Homo sapiens, Octopus vulgaris. Cytochrome $\mathrm{b}_{5}$ domain and His box are framed, degree of sequences conservation rises from light grey up to black (black, total conservation; dark grey, high conservation; middle grey, partial conservation; light grey, low conservation). For more details see Table 1. 


\section{$\Delta 5$-desaturase}

$\triangle 5$-desaturase catalyzes the conversion of DGLA (C 20:3, $\omega-6)$ to ARA (C 20:4, $\omega-3$ ) and the biosynthesis of EPA (C 20:5, $\omega-3)$. The genes for $\Delta 5$-desaturase have been isolated from many organisms e.g. Caenorhabditis elegans (Michaelson et al. 1998), various strain of Mortierella alpina (Tavares et al. 2011), Rattus norvegicus (Zolfaghari et al. 2001), Pavlova saliva (Zhou et al. 2007), Naegleria gruberi (Fritz-Laylin et al. 2010), Pythium irregulare (Hong et al. 2002a), Homo sapiens (Cho et al. 1999a), Octopus vulgaris (Monroig et al. 2011) etc. Figure 4 shows the alignment of these sequences. This type of desaturase contains cytochrome $b_{5}$ domain located on $\mathrm{N}$ terminal (typical motif HPGG). It contains three His box with

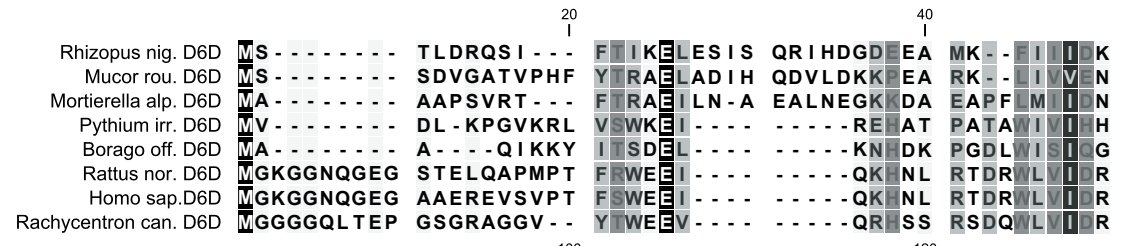

100 120

80

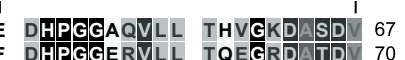

DHPGERVLL TQEGRDATDV 70
DHPGGS-VIL THVGKDCTDV 67 SHPGGS-VML TQAGED TD 60 RHPGGHRVIG HYSGED TDA 71 RHPGGLRVIS HYAGEDATEA 69 140

$\stackrel{160}{1} 129$

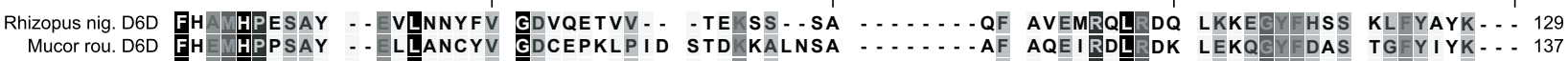
Mortierella alp. D6D FD FHPEAAW - . ETLANFYV GDIDES . . . . . DRAIKND . . . . . DF AAEVRKL AL FQSLGYYDSS KAYYAFK - . 127

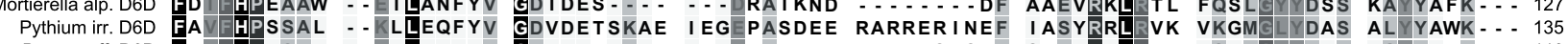

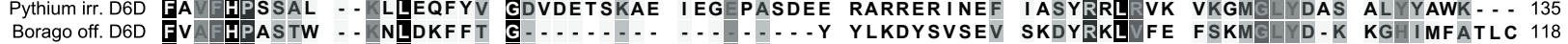
Borago off. D6D FVAFHPASTW
Rattus nor. D6D FR KFFHLDLDF VGKFLKPLLI

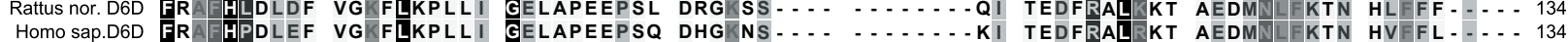
Rachycentron can. D6D FAAEHPDTF VQKFLKPLQI GELAASEPSQ DRNKNA - . . . . . . . A I IQDFHALAQ AESEGLFQTQ PLFFC - . . 132 180 200 220 240

Rhizopus nig. D6D - VLSTLAICI AGLS - - LLYA YGRTSTLAVV ASAITVGIFW QQCGWLAHDF GHHQCFEDRT WNDVLVVFLG NFCQGFSLSN 206 Mucor rou. D6D - VSTTLLVCI VGLA - I LKA WERESTLAVF IAASLVELFW QQCGWLAHDY AHYQVIKDPN VNN FLVTFG NLVQGFSLST 214

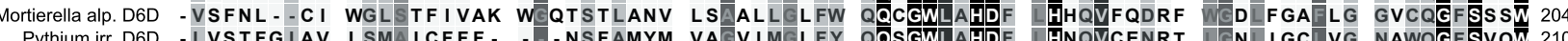
Pythium irr. D6D - LVSTFGIAV LSM I CFFF- - - NSFAMYM VA V I MELFY QQSGMLAHDF HNQVCENRT LGN IGCLVG NAWQGFSVQW 210

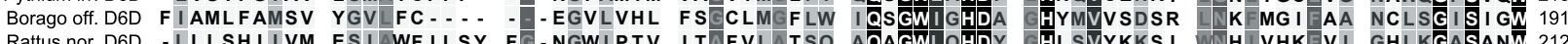

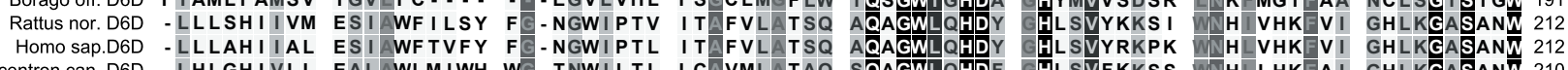

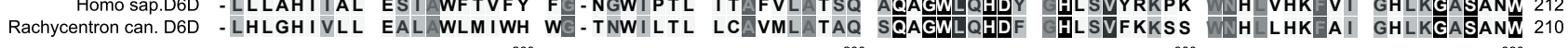

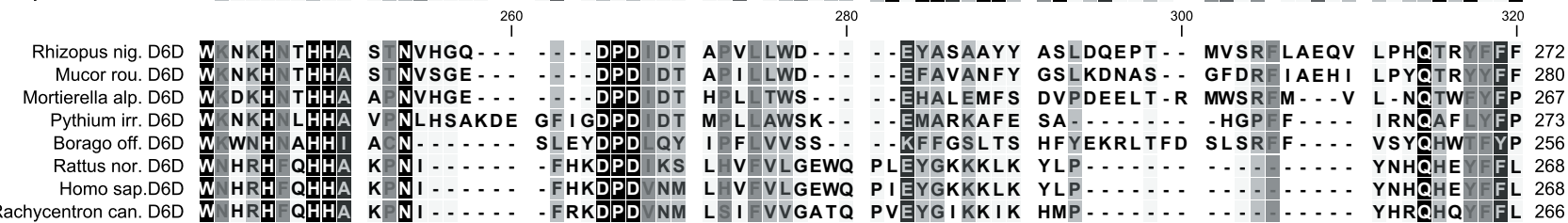
340 360 
typical patterns. The alignment pointed out that genes from multicellular organisms (Rattus, Homo, and Octopus) contain the short sequence right after the start codon. It suggests that these are the signal sequences that direct the protein to the specific cell organ. Expression of $\Delta 5$-desaturase gene from $M$. alpina in transgenic canola led to production unusual fatty acid such as taxoleic (C 18:2- 5, 9) and pinoleic acid (C 18:3- 5, 9,
12) that are products of conversion of oleic and linoleic acids with $\Delta 5$-desaturase (Knutzon et al. 1998).

\section{$\Delta 6$-desaturase}

$\Delta 6$-desaturase catalyzes the conversion of LA to GLA (C 18:3, $\omega-6)$ and conversion of $\operatorname{ALA}(\mathrm{C} 18: 3, \omega-3)$ to

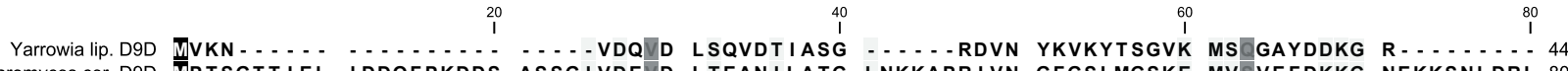

40
1

100 Saccharomyces cer. D9D IPTSGTTIEL IDDQFPKDDS ASSGIVDEVD LTEANILATG LNKKAPRIVN GFGSLMGSKE MVSVEFDKKG NEKKSNLDRL 80

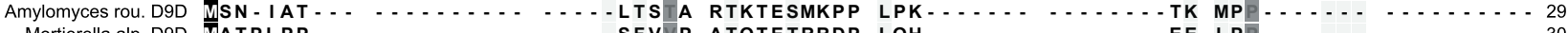

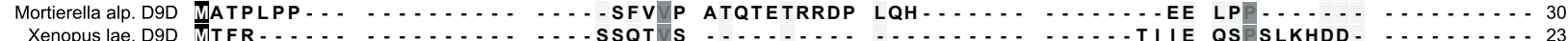
Xenopus lae. D9D

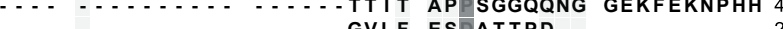
AnheraE 100 ${ }_{1}^{120}$ 140

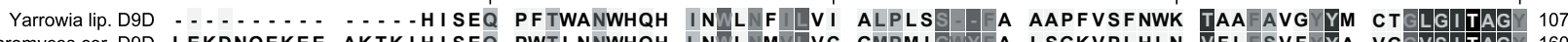

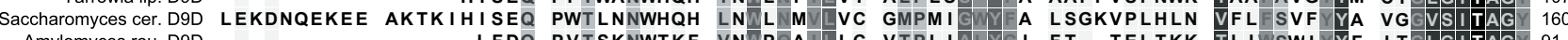

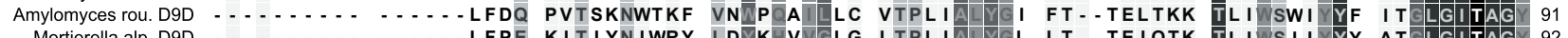

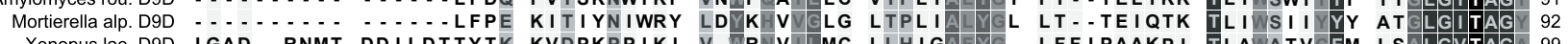
Xenopus lae. D9D IGAD--RNMT DDILDTTYTK KVDPKPPIKI V-WR VILMC LLHIGAFYG. LFFIPAAKPI TLA MATVEFM LS LLGVAG 99 Rattus nor. D9D WGADVRPEIK DDLYDPSYOD EEGPPPKLEY V-WR IILMA LLHIGALYG. ITLVPSCKVY TCLAYLYYV IS LLITAG 118 Antheraea per. D9D LGLPIQP... ......... IQ QADNRPK-QF V-WR IILFA YLHIAALYGG YLFLFHAKWQ TDI AYILYV MS GLGITAG 88 Antheraea
Arabidopsis tha. D9D $\ldots \ldots \ldots \ldots$
. 180 200 220 240
1

\begin{tabular}{|c|c|c|c|}
\hline Yarrowia lip. D9D & HR WAHRAY & $\triangle A L P D$ & LFGGGAVEGS \\
\hline ccharomyces cer. D9 & & $\overline{A H W}$ & I FGCA $\overline{S V E G S}$ \\
\hline Amylomyces rou. D9D & & ETD & FAGAGAVEGS \\
\hline Mortierella alp. D9D & & $\mathrm{FVL}$ & LLGAGĀVEGS \\
\hline Xenopus lae. D9D & & I FLA & VVNSMAFQND \\
\hline Rattus nor. D9D & & LFLII & I AN TMAFQND \\
\hline Antheraea per. D9D & A $\overline{H K S Y}$ & LILV & I FNTLAFQDS \\
\hline Arabidopsis tha. D9 & 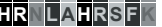 & YLLA & YCALLA IQ \\
\hline
\end{tabular}

Yarrowia lip. D9D TDI SDLNNDW VVRLGHKYYV YVIVFWADV Saccharomyces cer. D9D ADI TDMTDDW TIRFQHRHY LLMLL AFV Amylomyces rou. D9D ADVADLKADH V AFQHKYYP YFA G GFI Mortierella alp. D9D ADVDDLNKSK LVQNQHKNYL PLVLIMGVV Xenopus lae. D9D LDLSDLKA K V VMFERENYK LSILVMCFI

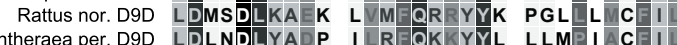

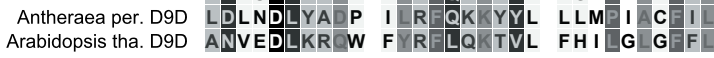

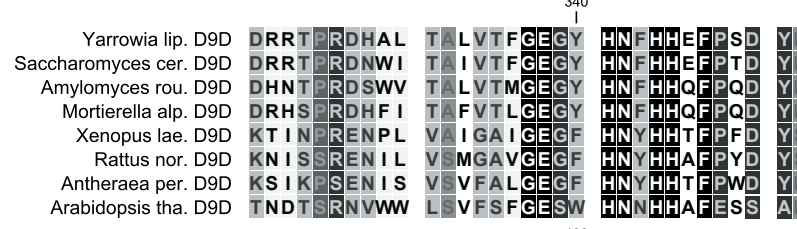

Arabidopsis tha. D9D TNDTSRNVWW LSVFSFGESW

420 Yarrowia lip. D9D DKWRNNLNWG IPIEQLPVIE FEEFQEQAK - - TRDLVLISG IVHDVSAFVE HHPGGKALIM Saccharomyces cer. D9D NKKKAKINWG PVLTDLPMWD KQTFLAKSK - ENKGLVIISG IVHDVSGYIS EHPGGETLIK Amylomyces rou. D9D QAQKAKLSYG TPLKDLPIYT WEEYQSLVLN DNKKWVLIEG VLYDVEEFMK EHPGGMKYLS Mortierella alp. D9D LEKKTKLQWG TPIADLPILS FEDYQHACKN DNKKWILLEG VVYDVADFMS EHPGGEKYIK

Xenopus lae. D9D

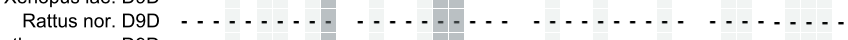

Antheraea per. D9D
Arabidopsis tha. D9D

520

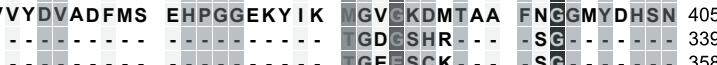

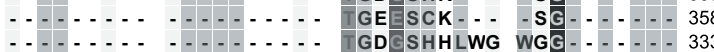
540

Yarrowia lip. D9D AGHNLLATME VSVIRGGMEV EVWKTAQNEK KDQNIVSDES GNRIHRAGLQ ATRVENPGMS GMAA 482 Saccharomyces cer. D9D AAQNVLADME VAVIK - . . - . . . . . ES KNSAIRMASK RGEIYE - . - . . . . . T GKFF 510 Amylomyces rou. D9D GTRNLLTSLR VGVLRNGMQV MT - . . . E EA -DATASLYDD SLEFDSKA - - . . . - ALF NKSK 452

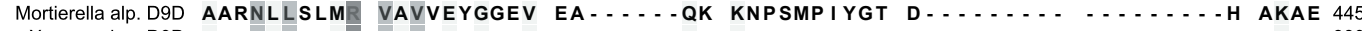

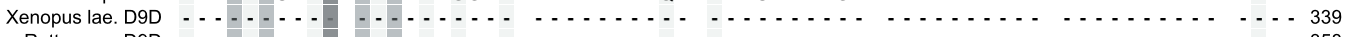

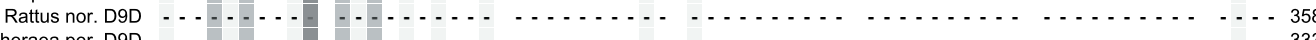
Antheraea per. D9D
Arabidopsis tha. D9D $\ldots \ldots \ldots$

Figure 6. Alignment of amino acid sequences of $\Delta 9$-desaturase proteins (D9D) from Yarrowia lipolytica, Saccharomyces cerevisiae, Amylomyces rouxii, Mortierella alpina, Xenopus laevis, Rattus norvegicus, Antheraea pernyi, Arabidopsis thaliana. Cytochrome $b_{5}$ domain and His box are framed, degree of sequences conservation rises from light grey up to black (black, total conservation; dark grey, high conservation; middle grey, partial conservation; light grey, low conservation). For more details see Table 1. 
stearidonic acid (SDA, C 18:4, $\omega-3$ ). Many genes coding this enzymes have been isolated and characterized e.g. Pythium irregulare (Hong et al. 2002b), Rhizopus nigricans (Lu et al. 2009), Rachycentron canadum (Zheng et al. 2009), Mucor rouxii (Laoteng et al. 2005b), Borago officinalis (Sayanova et al. 1997), Mortierella alpina (Sakuradani et al. 1999a), Rattus norvegicus (Aki et. al 1999), Homo sapiens (Cho et al. 1999b) etc. The partial sequences form Thaminidium elegans and various Mucor strains have been characterized in our laboratory (GenBank accession No. HM856138, HQ437169, HQ437170, HQ437171, HQ437172). The alignment of these sequences is presented on Figure 5. Each desaturase has the cytochrome $b_{5}$ domain present on $\mathrm{N}$-terminal and three His boxes with common pattern - $\mathrm{Q}$ instead of $\mathrm{H}$ in $3^{\text {rd }} \mathrm{His}$ box, two amino acid residues between His residues in $2^{\text {nd }}$ His box. The change of $Q$ to $\mathrm{H}$ in $3^{\text {rd }}$ His box leads to complete loss of activity of protein (Sperling et al. 2003). Expression of $\Delta 6$-desaturase gene from Cunnighamela echinulata in yeast strain Pichia pastoris led to production of $\gamma$-linolenic acid with yield $3 \%$ of total lipids and octadecadienoic acid (C 18:2, $\omega-9)$ in trace concentration. However, the most controversal changes were observed in other fatty acid that occurs naturally in this yeast strain. The content of heptadecenoic acid (C 17:1) increased 30 times, and the yield of $\alpha$-linolenic acid (C 18:3, $\omega-3$ ) was enhanced from 3 to $15 \%$ of total lipids. On the other hand, the striking decrease was observed in linoleic acid where its content dropped from 16 to $0.1 \%$ of total lipids (Xia et al. 2009). The expression of the very same gene isolated from Thamnidium elegans in the same host led only to production of $\gamma$-linolenic acid and there were no significant changes in content of other fatty acids (Wang et al. 2007). Expression of $\Delta 6$-desaturase gene from Mucor rouxii in the yeast Saccharomyces cerevisiae caused the desaturation of all available fatty acids without regard to chain length. This desaturase shows no substrate specificity (Na-Ranong et al. 2005). Zhou et al. (2006) carried out the heterelogic expression of $\Delta 6$-desaturase gene from plant Echium plantagineum to tobacco and Arabidopsis that currently synthesize linoleic and $\alpha$-linolenic acids. It is noteworthy that while the gene expression in Arabidopsis led to desaturation of both fatty acids, transformed tobacco preferentially transformed linoleic acid to GLA. These results indicate that the $\Delta 6$-desaturase specificity varies and depends not only on the origin of the gene, but also on the host. The further studies on substrate specificity of $\Delta 6$-desaturase may bring more light to the genetically-mediated production of desired PUFAs.

\section{9-desaturase}

$\Delta 9$ is the only desaturase that is spread through all type of organisms. In the nature it widely catalyses the conversion of stearic acid (C 18:0) to oleic acid (C 18:1, $\omega-9)$ as well as palmitic acid (C 16:0) to palmitoleic acid (C 16:1, n-7). The enzyme was probably the most important for maintenance of proper membrane fluidity of living organismsm during the evolution. Wongwathanarat (1999) reported that the yeast $\Delta 9$-desaturase activity, compared with other fatty acid desaturases, was mostly involved to changing the membranes fluidity during temperature shift. Hsieh and Kou (2005) support this hypothesis with experiment with two fishes Ctenopharyngodon idella and Chanos chanos. Plenty of genes coding this enzyme have been isolated and characterized in other various organisms e.g. Mortierella alpina (Sakuradani et al. 1999b), Amylomyces rouxii (Laoteng et al. 2005a) Saccharomyces cerevisiae (Stuckey et al. 1990), Yarrowia lipolytica (Xue et al. 2009), Arabidopsis thaliana (Fukuchi-Mizutani et al. 1998), Rattus norvegicus (Baba et al. 1994), Xenopus laevis (Klein et al. 2002), Antheraea pernyi (Wang et al. 2010) etc. Figure 6 represents the alignment of these sequences where the cytochrome $b_{5}$ domain is located at C-terminal end of protein. Genes from multicelluar organisms - arabidopsis, rat, oak and frog do not contain this domain. The reason of the cytochrome $b_{5}$ domain deletion from $\Delta 9$-desaturases is still unknown, but in a fact it was found only in the higher eukaryotes, whew diffusible cytochrome $b_{5}$ of the endoplasmic reticulum serves as electron donor in these cases (Uttaro 2006). Figure 7 also shows that the pattern of the His boxes corresponds to typical motif of $\Delta 9$-desaturase as follows: $1^{\text {st }}$ His box contains four amino acid residues between His residues and $3^{\text {rd }}$ His box contains $\mathrm{H}$ instead of Q. Expression of the $\Delta 9$-desaturase commonly yielded to higher amounts oleic acid. Nevertheless, Kajiwara et al. (2000) interestingly reported that overexpression of $\Delta 9$-desaturase protein in Saccharomyces cerevisiae increased the ethanol fermentation. Also, heterological expression of $\Delta 9$-desaturase in the tomato enhanced its resistance against powdery mildew (Wang et al. 1998).

\section{$\Delta 12$-desaturase}

$\Delta 12$-desaturase is enzyme that is responsible for conversion of oleic acid to linoleic acid. This enzyme is not presented in human or any animals and that makes linoleic acid essential for human health. It has been isolated from various type of organisms such as Mortierella alpina (Sakuradani et al. 1999c), Amylomyces rouxii (GenBankNo. AF533361), Aspergillus flavus (GenBank No. AY280867), Chlorella vulgaris (Suga et al. 2002), Borago officinalis (GenBank No. AF074324), Helianthus annus (Martinez-Rivas et al. 2001), Caenorhabditis elegans (Peyou-Ndi et al. 2000), Trypanosoma brucei (Petrini et al. 2004) etc. The motif of each His boxes does not display any exception from the typical pattern (Fig. 7). However, as it was mentioned above, the $\Delta 12$-desaturase does not contain the cytochrome $b_{5}$ domain. The reason for deletion of the cytochrome $b_{5}$ domain has not 
been explained yet. Since the $\Delta 12$-desaturase is enzyme that needs to accept the electrons for proper function, microsomal cytochrome $b_{5}$ might be involved to this process.

Peyou-Ndi et al. (2000) heterologically expressed $\Delta 12$ desaturase gene isolated from Caenorhabditis elegans into Saccharomyces cereviase. The transformed yeasts increased (by $40 \%$ ) conversion rate of palmitoleic and oleic acids to their consequent analogues with another double bond in cis- 12-position. It should be noted that this transformed strain showed higher resistance to ethanol and oxidative stress.

\section{Phylogenetic tree of fatty acid desaturases}

The phylogenetic tree of chosen fatty acids desaturases (Fig. 8) indicate following interesting fact:
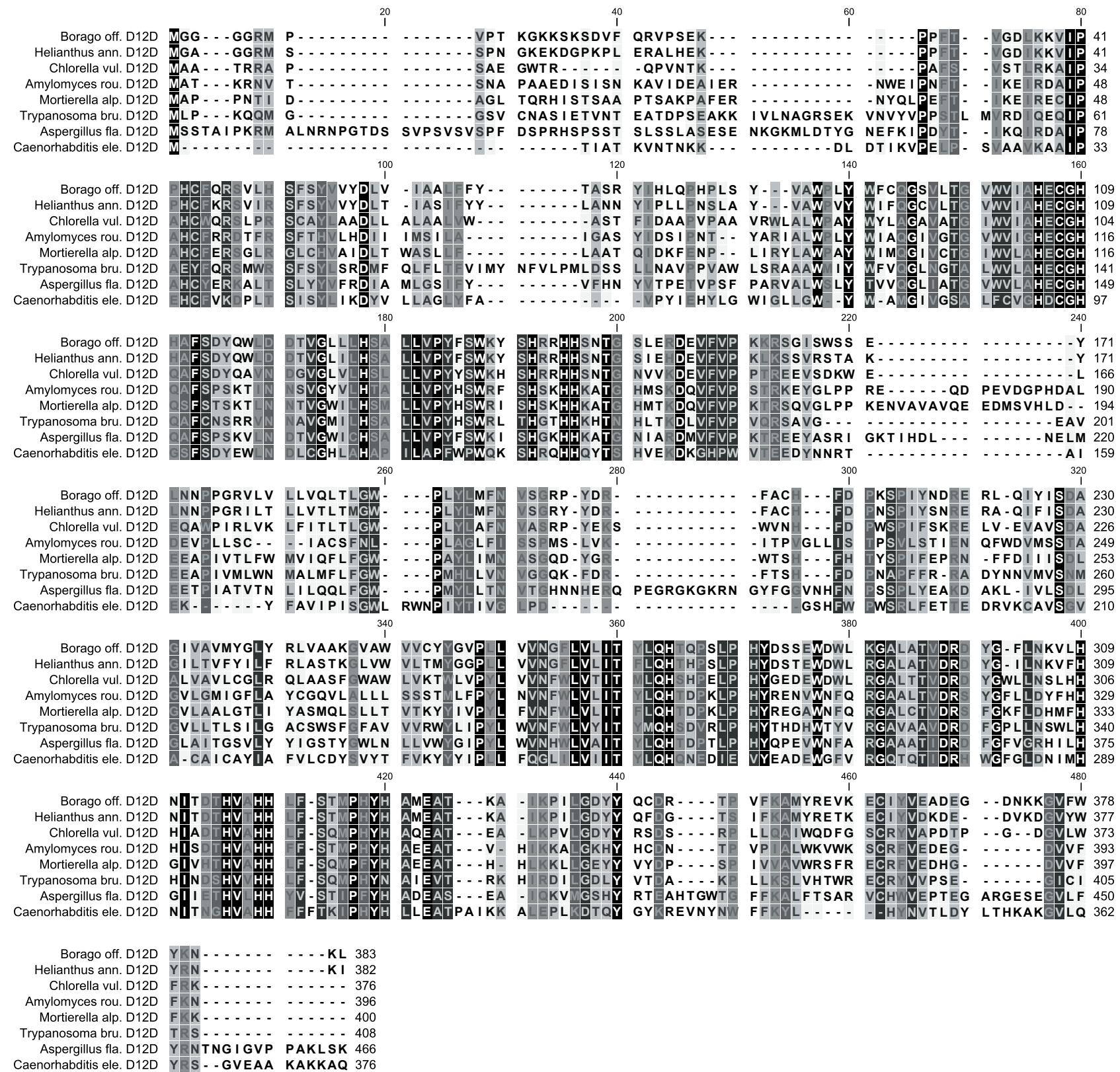

Figure 7. Alignment of amino acid sequences of $\Delta 12$-desaturase proteins (D12D) from Borago officinalis, Helianthus annuus, Chlorella vulgaris, Amylomyces rouxii, Mortierella alpina, Trypanosoma brucei, Aspergillus flavus, Caenorhabditis elegans. His box are framed, degree of sequences conservation raises from light grey up to black (black, total conservation; dark grey, high conservation; middle grey, partial conservation; light grey, low conservation). For more details see Table 1. 


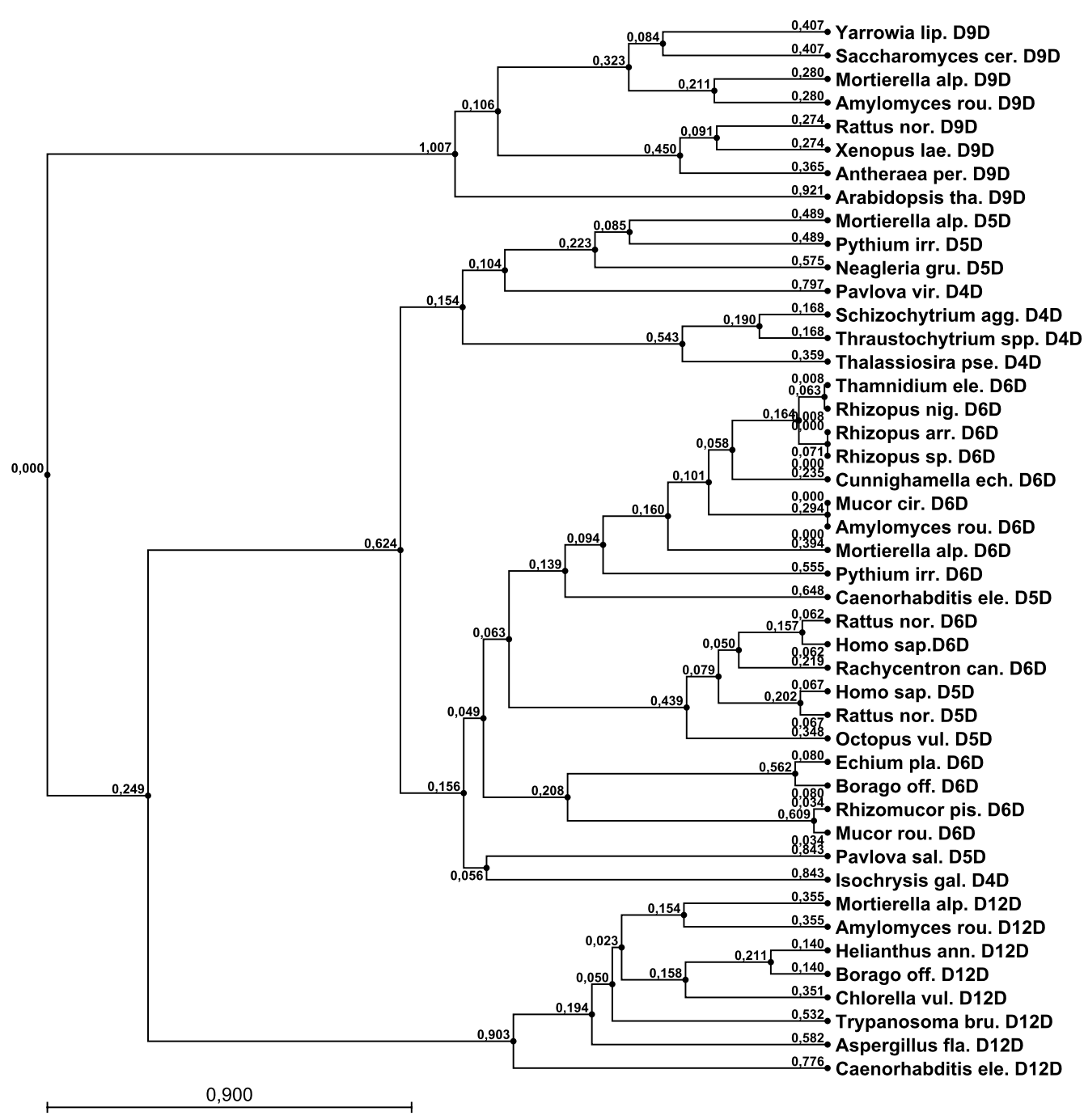

Figure 8. Phylogenetic tree of selected fatty acids desaturases. Phylogenetic tree was created by CLC Mainworkbech 5.1 (CLC Bio).

- The genes for membrane-bound desaturases can be divided into three big groups $-\Delta 9$ desaturases, $\Delta 12$ desaturases and "front-end" desaturases $(\Delta 6, \Delta 5, \Delta 4$ desaturases).

- $\Delta 9$ desaturases creates their own groups relatively distanced from the others. It could be assumed that these enzymes were the ancestor of all desaturases enzymes.

- The "front-end" desaturases cannot be separated into phylogenetic group based on the position specificity of enzyme, but they create small groups that are relative to taxonomy.

- It could be observed that fungal $\Delta 6$ desaturases from Mucor rouxiii and Rhizomucor pissilus are more close to plant $\Delta 6$ desaturases from Borago and Echium that to other fungal desaturases.

\section{Physiological consequences of PUFAs on cell membranes}

PUFAs are distributed to every cell membranes where are predominately esterified into the $s n$ - 2 position of phosphatidylcholine and phosphatidylethanolamine. PUFA effects on cell membrane functions have been noted and discussed widelyfrom the view of a) modifications of membrane fluidity, b) modifications of the activity of membrane bound enzymes, c) modifications of the number and affinity of receptors, d) modifications of the function of ion channels, and e) signal transduction (Yehuda et al. 2002; Hulbert et al. 2007; Abbott et al. 2012). Since the cell membranes are largely held together by van der Waals forces between fatty acyl chains, structural properties of these acyls (length and degree of unsaturation) play a key role in the membrane structure. The degree of unsaturation is particulary important because van 
der Waals forces are acutely sensitive to the distance between interacting acyl chains. For example, whereas stearic acid is estimated to be $0.25 \mathrm{~nm}$ in diameter, oleic acid has spatial width of $0.72 \mathrm{~nm}$ (Cook 1991). The cis-unsaturated bond thus interrupts van der Waals forces between membrane fatty acids by increasing distance between them and lowers the membrane crystallization temperature. Therefore PUFA incorporation into membrane phospholipids would have an effect on the formation and stability of the membrane microdomains. As mentioned, the tight packing density of lipids in liquid ordered microdomains is conferred by favorable van der Waals forces between saturated acyl chains to hydrogen bonding between various membrane-associated molecules. PUFAs do not pack well with these molecules (e.g. sterols) and therefore form a liquid disordered phase (Edidin 2003). Fatty acid composition in the membrane lipids would also cause a redistribution of protein between liquid ordered and liquid disordered the membrane microdomains (Wickner 1977) as well as modify membrane-associated enzyme activity (Wilschut et al. 1978) and molecular transport (Tsong et al. 1977). In addition, PUFA acyl chains can rapidly convert between various conformational states (Shaikh and Edidin 2006). High conformational flexibility of both n-3 and n-6 PUFA acyl chains alters the physical properties of the membrane, including lateral organization, hydrophobic match, curvature stress, and the lateral pressure density profile, which can modify protein function, trafficking, vesicle budding, and fusion. Acyl chain flexibility also differs between n-3 and n-6 PUFAs, which may have functional consequences. This provides the strong evidence that composition and changes of membrane fatty acids play important role in the modification of cell membrane physiology (Watkins and German 2002).

\section{Conclusion}

The desaturation is the key reaction in biosynthesis of PUFAs. Characterization of genes and proteins of fatty acid desaturase enzymes is necessary step for their further applications. The field of possible usage is very wide including medicine, agriculture and food/feed industry. From the technological point of view, one of the most important applications is preparation of transgene plants with usage in oil industry. In December 2009, first plant enriched with gene for $\Delta 6$-desaturase was introduced to American market. SONOVA 400 is dicotyledon plant from clade Asteridae, Carthamus tinctorius (safflower), transformed with gene for $\Delta 6$ - desaturase coming from fungi Mortierella alpina (Watkins 2010). Other technological possibilities are connected with preparation of highly oleaginous and highly specific microbial strains that could use low-cost agroindustrial wastes for effective conversion to either mi- crobial oil with tailor-made PUFA composition or cereals enriched with PUFAs prepared by solid state fermentations. These are the possibilities of cost lowering that can help to spread PUFAs in human dietary. All of these efforts may demonstrate enormous potential for applications of fatty acid desaturases and thus create new perspectives market "bio-based" PUFA oils or products.

Acknowledgement. The work was supported by grant VEGA 1/0975/12 from the Grant Agency of the Ministry of Education, Slovak Republic and by grants APVV-0662-11, APVV-0294-11 and VVCE-0064-07 from the Slovak Research and Development Agency, Slovak Republic.

\section{References}

Abbott S. K., Else P. L., Atkins T. A., Hulbert A. J. (2012): Fatty acid composition of membrane bilayers: Importance of diet polyunsaturated fat balance. Biochim. Biophys. Acta 1818, 1309-1317 http://dx.doi.org/10.1016/j.bbamem.2012.01.011

Aki T., Shimada Y., Inagaki K., Higashimoto H., Kawamoto S., Shigeta S., Ono K., Suzuki O. (1999): Molecular cloning and functional characterization of rat $\Delta 6$ fatty acid desaturase. Biochem. Bioph. Res. Co. 255, 575-579 http://dx.doi.org/10.1006/bbrc.1999.0235

Alonso D. L., Garcia-Maroto F., Rodriguez-Ruiz J., Garrido J. A., Vilches M. A. (2003): Evolutions of the membrane bound fatty acid desaturases, Biochem. Syst. Ecol. 31, 1111-1124 http://dx.doi.org/10.1016/S0305-1978(03)00041-3

Baba H., Fuss B., Watson J. B., Zane L. T., Macklin W. B. (1994): Identification of a novel mRNAs expressed in oligodendrocytes. Neurochem. Res. 19, 1091-1099 http://dx.doi.org/10.1007/BF00968721

Benatti P., Peluso G., Nicolai R., Calvani M. (2004): Polyunsaturated fatty acid; biochemical, nutritional and epigenetic properties, J. Am. Coll. Nutr. 23, 281-302 http://dx.doi.org/10.1080/07315724.2004.10719371

Certik M., Shimizu S. (1999): Biosynthesis and regulation of microbial polyunsaturated fatty acid production. J. Biosci. Bioeng. 87, 1-14 http://dx.doi.org/10.1016/S1389-1723(99)80001-2

Cook H. W. (1991): Fatty acid desaturation and chain elongation in eukaryotes. In: Biochemistry of Lipids, Lipoproteins and Membranes. (Eds. D. E. Vance, J. Vance), pp. 141-169, Elsevier Science Publisher, Amsterdam

Damude H. G., Kinney A. J. (2007): Enhancing plant seed oils for human nutrition. Plant. Physiol. 147, 962-968 http://dx.doi.org/10.1104/pp.108.121681

Diaz A. R., Mansila M. C., Vila A. J., Mednoza D. (2002): Membrane topology of the acyl-lipid desaturase from Bacillus subtilis. J. Biol. Chem. 277, 48099-48106 http://dx.doi.org/10.1074/jbc.M208960200

Edidin M. (2003): The state of lipid rafts: from model membranes to cells. Annu Rev. Biophys. Biomol. Struct. 32, 257-283 http://dx.doi.org/10.1146/annurev.biophys.32.110601.142439 
Fritz-Laylin L. K., Prochnik S. E., Ginger M. L., Dacks J. B., Carpenter M. L., Field M. C., Kuo A., Paredez A., Chapman J., Pham J., Shu S., Neupane R., Cipriano M., Mancuso J., Tu H., Salamov A., Lindquist E., Shapiro H., Lucas S., Grigoriev I. V., Cande W. Z., Fulton C., Rokhsar D. S., Dawson S. C. (2010): The genome of Naegleria gruberi illuminates early eukaryotic versatility. Cell 140, 631-642 http://dx.doi.org/10.1016/j.cell.2010.01.032

Fukuchi-Mizutani M., Tasaka Y., Tanaka Y., Ashikari T., Kusumi T., Murata N. (1998): Characterization of delta 9 acyl-lipid desaturase homologues from Arabidopsis thaliana. Plant Cell Physiol. 39, 247-253 http://dx.doi.org/10.1093/oxfordjournals.pcp.a029364

Hong H., Datla N., MacKenzie S. L., Qiu X. (2002a): Isolation and characterization of a $\Delta 5$ fatty acid desaturase from Pythium irregulare by heterelogous expression in Saccharomyces cerevisiae and oilseed crops. Lipids 37, 863-868 http://dx.doi.org/10.1007/s11745-002-0972-5

Hong H., Datla N., Reed D. W., Covello S., MacKenzie S. L., Qiu X. (2002b): High-level production of $\gamma$-linolenic acid in Brassica juncea using a $\Delta 6$ desaturase from Pythium irregulare. Plant Physiol. 129, 354-362 http://dx.doi.org/10.1104/pp.001495

Horrobin D. F. (1992): Nutritional and medical importance of gamma-linolenic acid. Prog. Lipid Res. 31, 163-194 http://dx.doi.org/10.1016/0163-7827(92)90008-7

Hsieh S. L., Kuo C. M. (2005): Stearoyl-CoA desaturase expression and fatty acid composition in milkfish (Chanos chanos) and grass carp (Ctenopharyngodon idella) during cold acclimation. Comp. Biochem. Physiol., Part B 141, 95-101

Hulbert A. J., Pamplona R., Buffenstein R., Buttemer W. A. (2007): Life and death: metabolic rate, membrane composition and life span of animals. Physiol. Rev. 87, 1175-1213 http://dx.doi.org/10.1152/physrev.00047.2006

Chen R., Matsui K., Ogawa M., Oe M., Ochiai M., Kawashima H., Sakuradani E., Shimizu S., Ishimoto M., Hayashi M., Murooka Y., Tanaka Y. (2006): Expression of $\Delta 6, \Delta 5$ and GLELO elongase genes from Mortierella alpina for production of arachidonic acid in soybean [Glycine max (L.)] seeds. Plant Science, 170, 399-406 http://dx.doi.org/10.1016/j.plantsci.2005.09.006

Cho H. P., Nakamura M., Clarke S. D. (1999a): Cloning, expression and fatty acid regulation of the human $\Delta 5$ desaturase. J. Biol. Chem. 274, 37335-37339 http://dx.doi.org/10.1074/jbc.274.52.37335

Cho H. P., Nakamura M., Clarke S. D. (1999b): Cloning, expression and nutritional regulation of the mammalian $\Delta 6$ desaturase. J. Biol. Chem. 274, 471-477 http://dx.doi.org/10.1074/jbc.274.1.471

Jump D. B. (2002): The biochemistry of $n-3$ polyunsaturated fatty acids. J. Biol. Chem. 277, 8755-8758 http://dx.doi.org/10.1074/jbc.R100062200

Kajiwara S., Aritomi T., Suga K., Ohtaguchi K., Kobayashi O. (2000): Overexpression of the OLE1 gene enhances ethanol fermentation by Saccharomyces cerevisiae. Appl. Microbiol. Biot. 53, 568-574 http://dx.doi.org/10.1007/s002530051658

Kinney A. J., Cahoon E. B., Damude H. G., Hitz W. D., Kolar C. W., Liu Z. B. (2004): Production of very long chain polyunsaturated fatty acids in oilseed plants. PCT Int Appl WO2004071467

Klein S. L., Strausberg R. L., Wagner L., Pontius J., Clifton S. W., Richardson P. (2002): Genetic and genomic tools for Xenopus research: The NIH Xenopus initiative. Dev. Dynam. 225, 384-391 http://dx.doi.org/10.1002/dvdy.10174

Knutzon D. S., Thurmond J. M., Huang Y., Chaudhary S., Bobik E. G., Chan G. M., Kirchner S. J., Mukerji P. (1998): Identification of $\Delta 5$ desaturase from Mortierella alpina by heterelogous expression in baker's yeast and canola. J. Biol. Chem. 273, 29360-29366 http://dx.doi.org/10.1074/jbc.273.45.29360

Laoteng K., Certik M. (2010): Biotechnological production and application of high-value microbial oils. In: Industrial Fermentation. (Eds. J. Krause, O. Fleischer), pp. 187-215, Nova Science Publishers, Inc.

Laoteng K., Cheevadhanarak S., Tanticharoen M., Maresca B. (2005a): Promoter analysis of Mucor rouxii delta9-desaturase: its implication for transcriptional regulation in Saccharomycas cerevisiae. Biochem. Bioph. Res. Co. 335, 400-405 http://dx.doi.org/10.1016/j.bbrc.2005.07.094

Laoteng K., Ruenwai R., Tanticharoen M., Cheevadhanarak S. (2005b): Genetic modification of essential fatty acids biosynthesis in Hansenula polymorpha. FEMS Microbiol. Lett. 245, 169-178 http://dx.doi.org/10.1016/j.femsle.2005.03.006

Los D. A., Murata N. (1998): Structure and expression of fatty acid desaturases, Biochim. Biophys. Acta 1394, 215-218

Lu X., Li J. N., Chai Y. R., Zhang X. K. (2009): Identification and characterization of a novel $\Delta 6$-fatty acid desaturase gene from Rhizopus nigricans. Mol. Biol. Rep. 36, 2291-2297 http://dx.doi.org/10.1007/s11033-009-9447-0

Man W. C, Miyazaki M., Chu K., Ntambi J. M. (2006): Membrane topology of mouse stearoyl-CoA desaturase 1. J. Biol. Chem. 281, 1251-1260 http://dx.doi.org/10.1074/jbc.M508733200

Martinez-Rivas J. M., Sperling P., Luehs W., Heinz E. (2001): Spatial and temporal regulation of three different microsomal varieties of sunflower. Mol. Breed. 8, 159-168 http://dx.doi.org/10.1023/A:1013324329322

Michaelson L. V., Napier J. A., Lewis M., Griffiths G., Lazarus C. M., Stobart A. K. (1998): Functional identification of a fatty acid $\Delta 5$ desaturase gene from Caenorhabditis elegans. FEBS Lett. 439, 215-218 http://dx.doi.org/10.1016/S0014-5793(98)01385-4

Monroig O., Navarro J. C., Dick J. R., Alemany F., Tocher D. R. (2011): Identification of a $\Delta 5$-like fatty acid desaturase from the cephalopod Octopus vulgaris (Cuvier 1797) involved in the biosynthesis of essential fatty acid. Mar. Biotechnol. 14, 411-422 http://dx.doi.org/10.1007/s10126-011-9423-2

Na-Ranong S., Laoteng K., Kittakoop P., Tanticharoen M., Cheevadhanrak S. (2005): Substrate specificity and preference of D6-desaturase of Mucor rouxii. FEBS Lett. 579, 2744-2748 http://dx.doi.org/10.1016/j.febslet.2005.04.010

Pereira S. L., Leonard A. E., Huang Y. S., Chuang L. T., Mukerji P. (2004): Identification of two novel microalgal enzymes in- 
volved in the conversion of the $\omega 3$-fatty acid, eicosapentaenoic acid, into docosahexaenoic acid. Biochem. J. 384, 357-366 http://dx.doi.org/10.1042/BJ20040970

Pereira S. L., Leonard A. E., Mukerji P. (2003): Recent advances in the study of fatty acid desaturases from animals and lower eukaryotes. Prostag. Leukotr. Ess. 68, 97-106 http://dx.doi.org/10.1016/S0952-3278(02)00259-4

Petrini G. A., Altabe S. G., Uttaro A. D. (2004): Trypanosoma brucei oleate desaturase may use a cytochrome b5-like domain in another desaturase as an electron donor. Eur. J. Biochem. 271, 1079-1086 http://dx.doi.org/10.1111/j.1432-1033.2004.04005.x

Peyou-Ndi M. M., Watts J. L., Browse J. (2000): Identification and characterization of an animal $\Delta 12$ fatty acid desaturase gene by heterelogous expression in Saccharomyces cerevisiae. Arch. Biochem. Biophys. 376, 399-408 http://dx.doi.org/10.1006/abbi.2000.1733

Qi B., Beaudoin F., Fraser T., Stobart A. K., Napier J. A., Lazarus M. (2002): Identification of a cDNA encoding a novel C18- $\Delta 9$ polyunsaturated fatty acid-specific elongating activity from the docosahexanoic acid (DHA)-producing microalga, Isochrysis galbana. FEBS Lett. 510, 159-165 http://dx.doi.org/10.1016/S0014-5793(01)03247-1

Qiu X., Meesapyodsuk D. (2009): Biosynthesis of unusual fatty acids in microorganisms and their production in plants. In: Biocatalysis and Agricultural Biotechnology. (Eds. Ch. T. Hou and Jei-Fu Shaw), pp. 133-142, CRC Press

Qiu X., Hong H., MacKenzie S. L. (2001): Identification of a $\Delta 4$ fatty acid desaturase from Thraustochytrium sp. involved in the biosynthesis of docosahexanoic acid by heterelogous expression in Saccharomyces cerevisiae and Brassica juncea. J. Biol. Chem. 276, 31561-31566 http://dx.doi.org/10.1074/jbc.M102971200

Sakuradani E., Kobayashi M., Ashikari T., Shimizu S. (1999c): Identification of delta12-fatty acid desaturase from arachidonic acid-producing Mortierella fungus by heterologous expression in the yeast Saccharomyces cerevisiae and the fungus Aspergillus oryzae. Eur. J. Biochem. 261, 812-820 http://dx.doi.org/10.1046/j.1432-1327.1999.0033

Sakuradani E., Kobayashi M., Shimizu S. (1999a): $\Delta 6$ fatty acid desaturase from an arachidonic acid- producing Mortierella fungus, gene cloning and its heterelogous expression in a fungus Aspergillus. Gene 238, 445-453 http://dx.doi.org/10.1016/S0378-1119(99)00359-5

Sakuradani E., Kobayashi M., Shimizu S. (1999b): $\Delta 9$ fatty acid desaturase from arachidonic acid- producing fungus. Eur. J. Biochem. 260, 208-216 http://dx.doi.org/10.1046/j.1432-1327.1999.00131.x

Sayanova O. V., Smith M. A., Lapinskas P., Stobart A. K., Dobson, G., Christie, W.W., Shewry, P. R, Napier, J. A. (1997): Expression of a borage desaturase cDNA containing an $\mathrm{N}$-terminal cytochrome b5 domain results in the accumulation of high levels of D6-desaturated fatty acids in transgenic tobacco. Proc. Natl. Acad. Sci. U.S.A. 94, 4211-4216 http://dx.doi.org/10.1073/pnas.94.8.4211

Shaikh, S. R., Edidin M. (2006): Polyunsaturated fatty acids, membrane organization, $\mathrm{T}$ cells, and antigen presentation. Am. J. Clin. Nutr. 84, 1277-1289
Shanklin J., Cahoon E. B. (1998): Desaturation and related modifications of fatty acids. Annu Rev. Plant Phys. 68, 107-112

Spector A. A. (1999): Essentiality of fatty acids. Lipids 34, S1-3 http://dx.doi.org/10.1007/BF02562220

Sperling P., Ternes P., Zank T. K., Heinz E. (2003): The evolution of desaturases. Prostag. Leukotr. Ess. 68, 73-95 http://dx.doi.org/10.1016/S0952-3278(02)00258-2

Stuckey J. E., McDonough V. M., Martin C. E. (1990): The OLE1 gene of Saccharomyces cerevisiae encodes the $\Delta 9$ fatty acid desaturase and can be functionally replaced by the art stearoylCoA desaturase gene. J. Biol. Chem. 268, 20144-20149

Suga K., Honjoh K., Furuya N., Shimizu H., Nishi K., Shinohara F., Hirabaru Y., Maruyama I., Miyamoto T., Hatano S., Lio M. (2002): Two low-temperature-inducible Chlorella genes for $\Delta 12$ and $\omega-3$ fatty acid desaturase (FAD): isolation of $\Delta 12$ and $\omega-3$ fad cDNA clones, expression of $\Delta 12$ fad in Saccharomyces cerevisiae and expression of $\omega-3$ fad in Nicotiana tabacum. Biosci. Biotech. Bioch. 66, 1314-1327 http://dx.doi.org/10.1271/bbb.66.1314

Tavares S., Grotkjaer T., Obsen T., Haslam R. P., Napier J. A., Gunnarson N. (2011): Metabolic engineering of Saccharomyces cerevisiae for production of eicosapentaenoic acid, using novel delta-5 desaturase Paramecium tetraurelia. Appl. Environ. Microb. 77, 1854-1861 http://dx.doi.org/10.1128/AEM.01935-10

Tonon T., Sayanova O., Michaelson L. V., Qing R., Harvey D., Larson T. R., Li Y., Napier J. A., Graham I. A. (2005): Fatty acid desaturases from the microalga Thalassiosira pseudonana. FEBS J. 272, 3401-3412 http://dx.doi.org/10.1111/j.1742-4658.2005.04755.x

Tsong T. Y., Greenberg M., Kanehisa M. I. (1977): Anesthetic action of membrane lipids. Biochem. 16, 3115-3121 http://dx.doi.org/10.1021/bi00633a012

Uttaro A. D. (2006): Biosyntesis of polyunsaturated fatty acids in lower eukaryotes. IUBMB Life 58, 563-571 http://dx.doi.org/10.1080/15216540600920899

Wallis J. G., Browse J. (1999): The $\Delta 8$-desaturase of Euglena gracilis: alternative pathway for synthesis of 20-carbon polyunsaturated fatty acid. Arch. Biochem. Biophys. 365, 307-316 http://dx.doi.org/10.1006/abbi.1999.1167

Wang C., Chin C. K., Chen A. (1998): Expression of yeast $\Delta 9$ desaturase gene in tomato enhances its rezistence to powdery mildew. Physiol. Mol. Plant P. 52, 371-383 http://dx.doi.org/10.1006/pmpp.1998.0158

Wang D., Li M., Wei D., Cai Y., Zhang Y., Xing L. (2007): Identification and functional characterization of the delta 6-fatty acid desaturase gene from Thamnidium elegans. J. Eukaryot. Microbiol. 54, 110-117 http://dx.doi.org/10.1111/j.1550-7408.2006.00136.x

Wang H. L., Lienard M. A., Zhao C. H., Wang C. Z., Lofstedt C. (2010): Neofunctionalization in an ancestral insect desaturase lineage led to rare $\Delta 6$ pheromone signals in the Chinese tussah silkworm. Insect Biochem. Molec. 40, 742-751 http://dx.doi.org/10.1016/j.ibmb.2010.07.009

Watkins S. M., German J. B. (2002): Unsaturated fatty acids. In: Food Lipids. (Eds. C. C. Akoh, D. B. Min and M. Dekker), pp 559-588, New York http://dx.doi.org/10.1201/9780203908815.ch18 
Watkins C. (2010): First high-GLA safflower oil on market. Inform. 21, 338-339

Wickner W. T. (1977): Role of hydrophobic forces in membrane protein asymmetry. Biochem. 16, 254-258 http://dx.doi.org/10.1021/bi00621a015

Wilschut J. C., Regts J., Westenberg H., Scherphof G. (1978): Action of phospholipases A2 on phosphatidyl choline bilayers. Effect of the phase transition, bilayer curvatures and structural defects. Biochim. Biophys. Acta 508, 185-196 http://dx.doi.org/10.1016/0005-2736(78)90324-3

Wongwathanarat P., Michaelson L. V., Carter A. T., Lazarus C. M., Griffith G., Stobart A. K., Archer D. B., MacKenzie D. A. (1999): Two fatty acid $\Delta 9$ - desaturases genes, ole1 and ole2, from Mortierella alpina complement the yeast ole1 mutation. Microbiology 145, 2939-2946

Xia W., Zhang Y., Wang P., Huang F., Chen H., Jiang M. (2009): Production of gamma-linolenic acid in Pichia pastoris by expression of a delta- 6 desaturase gene from Cunninghamella echinulata. J. Microbiol. Biotechn. 19, 1098-1102

Xu Y., Niu Y., Kong J. (2011): Heterelogous overexpression of a novel $\Delta 4$ desaturase gene from the marine microalga Pavlova viridis in Escherichia coli as a Mistic fusion. World J. Microb. Biot. 27, 2931-2937 http://dx.doi.org/10.1007/s11274-011-0776-5

Xue Z., Yadav N. S., Zhu Q. Q. (2009): Optimized strains of Yarrowia lipolytica for high eicosapentaenoic acid production. PCT Int Appl WO2009046231

Yehuda S., Rabinovitz S., Carasso R. L., Mostofsky D. I. (2002): The role of polyunsaturated fatty acids in restoring the aging neuronal membrane. Neurobiol. Aging 23, 843-853
http://dx.doi.org/10.1016/S0197-4580(02)00074-X

Zank T., Bauer J., Cirpus P., Abbadi A., Heinz E., Qiu X., Vrinten P., Sperling, P., Domergue F., Meyer A., Kirsch J. (2005): Method for the production of multiply-unsaturated fatty acids in transgenic organisms. PTC Int Appl WO2005012316

Zheng X., Ding Z., Xu Y., Monroig O., Morais S., Tocher D. R. (2009): Physiological roles of fatty acyl desaturases and elongases in marine fish: Characterisation of cDNAs of fatty acyl $\Delta 6$ desaturase and elovl5 elongase of cobia (Rachycentron canadum). Aquaculture 290, 122-131

http://dx.doi.org/10.1016/j.aquaculture.2009.02.010

Zhou X., Robert S., Singh S., Green A. (2006): Heterologous production of GLA and SDA by expression of an Echium plantagineum D6-desaturase gene. Plant Sci. 170, 665-673 http://dx.doi.org/10.1016/j.plantsci.2005.10.021

Zhou X. R., Robert S. S., Petrie J. R., Frampton D. M., Mansour M. P., Blackburn S. I., Nichols P. D., Green A. G., Singh S. P. (2007): Isolation and characterization of genes from the marine microalga Pavlova salina encoding three front-end desaturases involved in docosahexaenoic acid biosynthesis. Phytochemistry 68, 785-796

http://dx.doi.org/10.1016/j.phytochem.2006.12.016

Zolfaghari R., Cifelli C. J., Banta M. D., Ross A. C. (2001): Fatty acid delta(5)-desaturase mRNA is regulated by dietary vitamin A and exogenous retinoic acid in liver of adult rats. Arch. Biochem. Biophys. 391, 8-15 http://dx.doi.org/10.1006/abbi.2001.2361

Received: October 19, 2012

Final version accepted: May 16, 2013 